\title{
Client Satisfaction to Referral Service and Associated Factors Among Health Centers in Tigray, Ethiopia, 2019
}

\author{
Fre Gebremeskel' \\ Embeba Teklay ${ }^{2}$ \\ Yonas Anagaw' \\ Menaseb Gebrehaweria' \\ Abadi Hailay' \\ 'Department of Public Health, College of \\ Medicine and Health Science, Adigrat \\ University, Adigrat, Tigray, Ethiopia; \\ ${ }^{2}$ School of Public Health, College of \\ Health Sciences, Aksum University, \\ Aksum, Tigray, Ethiopia
}

Correspondence: Fre Gebremeskel Department of Public Health, College of Medicine and Health Science, Adigrat University, P.O.Box:50, Adigrat, Ethiopia Tel +251924862758

Email fregeriel43@gmail.com
Purpose: Even though referral is a major public health issue in the sub-Saharan countries including Ethiopia, there is limited data particularly in the study area. So, this study was aimed to assess client satisfaction with referral service and associated factors.

Objective: To assess client satisfaction to referral service and associated factors among Health Centers in Tigray, Ethiopia, 2019.

Methods and Materials: This was an institutional-based cross-sectional study carried out among Health Centers selected using simple a random sampling technique from February 2019 to April 2019. A total of 421 referred individuals were proportionally allocated to eight health centers and interviewed using pretested 5-point Likert scale structured questionnaire. After data collection, it was entered using Epi Info then transferred to Statistical Package for Social Sciences (SPSS) for the purpose of analysis. Factors associated with the satisfaction toward referral service were assessed using binary logistic regression. Statistically significant variables at the bivariate logistic regression analysis were regarded as nominees for multivariable analysis. The strength of the association of factors with satisfaction toward referral was determined by computing crude odds ratio (COR) and the adjusted odds ratio (AOR) with a 95\% confidence interval (CI). P-value $<0.05$ was considered statistically significant.

Results: In this study, $47 \%$ of referred patients were satisfied with the referral of Health Centers. Residence ( $\mathrm{AOR}=2.2 \mathrm{CI}=1.3,1.5)$, age ( $\mathrm{AOR}=3.1 \mathrm{CI}=2.3,6.4)$, and educational status $(\mathrm{AOR}=2.1 \mathrm{CI}=1.7,4.9)$ were statistically significant factors.

Conclusion: Significant clients were dissatisfied with the referral of Health Centers. Age, educational status, and residences were statistically significant factors. So, the Health Centers management and health care provider should work to reduce time spent to get a referral, reduce challenges in the referral process, increase helping and giving responsibility for the referred clients, improve communication.

Keywords: satisfaction, referral, Ethiopia

\section{Introduction}

Since 1990, Health care industries have seen current changes towards continuous quality improvement. Health care managers incorporate patient-centered care as a major component in the health care mission after the Donabedian's declaration for incorporating patient perception into quality assessment. ${ }^{1}$

Currently, the health care managers changed in the direction of a market-driven approach of changing patient satisfaction study into a quality improvement instrument for overall organizational performance. ${ }^{2}$ 
Determination of the most important contributor to overall satisfaction can assist health care providers in improving care. Moreover, Patient Satisfaction has emerged as an increasingly key criteria in the evaluation of health care quality. ${ }^{2}$

As a result of poor quality of health care, five million people die each year in low- and middle-income countries. $^{3}$ It is a leading, preventable killer of people around the globe and is three times higher as many people annually die than HIV and malaria combined. ${ }^{3}$

Based on the study done in Iraq $67 \%$ of patients were satisfied with the referral process of primary health care. ${ }^{4}$ The sex of the client was a statistically significant factor in which females were highly satisfied than males. But there was no association between the other socio-demographic factors and referral satisfaction. ${ }^{4}$ A similar study done in Nigeria also showed that $53.2 \%$ of patients were satisfied with the referral process of primary care. ${ }^{5}$ Difficulty in obtaining referral request, delayed response, getting approval was time-consuming and difficult, and the hospital did not communicate with referred health facility on time were the possible reasons described for the dissatisfaction. ${ }^{5}$

Ethiopia recently introduced a three-tier health care delivery system in which 1 woreda (district) includes a primary hospital (with population coverage of 100,000 people), health centers $(1 / 25,000$ population), and their satellite health posts (1/5000 population) connected to each other by a referral system. ${ }^{6}$ Based on the studies, referral rate is high in Ethiopia. ${ }^{7}$ In addition, $82 \%$ were self-referral. ${ }^{8}$ Referral challenges include shortage of Infrastructure, shortage of human resource, the problem of health information system, and challenge of financial resource. ${ }^{9}$

In Ethiopia, cancer accounts for $5.8 \%$ of total national death of which $80 \%$ of them diagnosed at an advanced stage. ${ }^{10}$ The reasons explained for the delay were low awareness of cancer signs and symptoms, poorly structured referral system of health facilities. ${ }^{9}$ In addition to this, maternal death is still high in which the majority of death was reported from the Tigray region, Ethiopia. ${ }^{6}$ Weak referral especially at the health center level was identified to be a major reason for the unacceptably high maternal mortality and morbidity in Ethiopia. ${ }^{6}$

As far as we know, generally, the referral is undertheorized, under-documented, and understudied particularly in the study area. ${ }^{11}$ Moreover, the available study was done in hospitals even though the referral gap was reported from the health center side. ${ }^{11}$ So, this study was intended to assess client satisfaction with referral service and associated factors among Health Centers. The result of this study will help the health experts, health service managers, and other stakeholders as input data in decisionmaking regarding the referral system. Moreover, it may help in designing strategies and interventions regarding the referral system.

\section{Methods and Materials}

\section{Study Design, Area, and Period}

An institution-based cross-sectional study design was carried out from February 2019 to April 2019 among Health Centers in the Eastern Zone of the Tigray region. Tigray is one of the national regional states of Ethiopia. The Eastern zone's zonal town is Adigrat which is located $900 \mathrm{~km}$ away from Addis Ababa, the capital city of Ethiopia. The Eastern Zone is bordered on the East by the Afar region, on the South by the South Eastern Zone, on the West by Central Zone, and on the North by Eritrea. It has a total population size of $755,343(359,638$ men and 395,705 women). It has two general Hospitals, five primary hospitals, and forty-five Health Centers. This study was conducted from February 2019 to April 2019.

\section{Populations}

Sources population: All referred patients by Health Centers in the Eastern Zone of the Tigray region.

Study population: All referred patients by selected Health Centers in the Eastern Zone of the Tigray during the data collection period.

\section{Eligibility Criteria}

Inclusion criteria: All referred patients by health centers with standard referral papers were included in this study.

Exclusion criteria: Seriously ill patients without attendants, patients aged less than eighteen were excluded from the study.

\section{Sample Size Determination and Sampling Procedure}

In this study, the sample size was computed for the two specific objectives of the magnitude and factors. For the first objective (magnitude) sample size was calculated using single population formula with the assumption of $\mathrm{Z} \alpha / 2=1.96$ (the standard score with a $95 \%$ confidence level for two sides), $\mathrm{d}=$ degree of accuracy desired to 
set at $(5 \%), \mathrm{P}=53.2 \%$ (the proportion of patient satisfaction) study done in Nigeria. The double population proportion formula was performed to compute sample size for the second objective (factors) with the assumptions of power $(80 \%)$, CI of $95 \%$, a margin of error $(5 \%)$, and 1:1 ratio of exposed to unexposed using open Epi Info 7 Statcalc. Finally, the 421 maximum sample size calculated from the first objective was used after adding a 10\% nonresponse rate. Eight Health Centers were selected randomly. The total sample size was proportionally allocated to the eight Health Centers based on the average number of clients referred to the Hospital six months prior to the start of the study. Then, study participants were recruited using a systematic random sampling method. In addition, simple random sampling was done for the initial client to get a starting point.

\section{Data Collection Tool and Procedure}

Pretested structured 5-point Likert questionnaire was used to collect the data using face-to-face interviews. It was designed to measure socio-demographic characteristics, satisfaction toward referral, and factors affecting it. The satisfaction questions contain a total of fourteen questions with seven components which include referral process, treatment given at the health center, communication, time spent to get the referral, service provided, discharge process, and overall satisfaction. The referral service satisfaction-related questions were developed from the Donabedian quality assessment framework and similar literature. The questions were presented using a 5-point Likert scale (1-very dissatisfied, 2-dissatisfied, 3-neutral, 4 -satisfied, and 5 very satisfied). The data collection was carried out by two midwives and was supervised by one health officer after giving two-day training.

\section{Data Quality Control}

To assure the quality of the data, the questionnaire was translated to the local language (Tigrigna) then translated back to English. The questionnaire was pretested in 5\% (21) of the study participants out of the study area prior to the data collection for detection of any difference and to set the appropriate time. Then, the necessary correction was made accordingly. During the data collection process, the filled questionnaire was checked for its completeness by the principal investigator every day. Data entry format template was produced and programmed. Finally, data were cleaned for missing data using a frequency table before entering the analysis. The validity of this study was assured through continuous input and feedback from the supervisor. Cronbach, s alpha coefficient (0.81) was calculated to check the instrument reliability (internal reliability).

\section{Data Management and Analysis}

The collected data were coded, entered using Epi info version 7.2.1.0 then exported to SPSS version 25 for the analysis purpose. Both binary and multivariable logistic regression analyses were employed to identify statistically significant factors with the referral satisfaction. The variables in bivariable analysis with $\mathrm{p}<0.2$ were entered into multivariable logistic regression. The strength of the association of the factors with the referral satisfaction was determined by computing crude odds ratio (COR) and the adjusted odds ratio (AOR) with a 95\% confidence interval (CI). P-value $<0.05$ was considered as statistically significant. Finally, the analyzed data were organized and presented using a table, graph, and text accordingly. Hosmer and Lemeshow test at a value of $>0.05$ was performed to check the goodness of fit for the final logistic model.

\section{Operational Definitions}

Patient satisfaction: is the feeling of pleasure or disappointment as a result of a given service with a comparison of the performance of the institution's care against the expectation of the patient. Patients who rated $<$ $75 \%$ from the item of patient satisfaction toward referral questionnaire were classified under "unsatisfied", and the patients who rated $>$ _ $75 \%$ from the item of patient satisfaction toward referral questionnaire were classified under "satisfied". 11

\section{Result}

\section{Socio-Demographic Characteristics of the Study Participants}

In this study, the response rate was $98.5 \%$. Of those, More than half $(56.7 \%)$ were females. About one in ten respondents $(30.1 \%)$ were in the age group of $25-34$. About twothirds of the study respondents (66.8\%) were married. Above one-fifth of the study respondents (26.4\%) were housewives in occupation. Above three -fourth of the study participants (76.9\%) were orthodox by religion. Nearly six in ten $(61.4 \%)$ of the respondents were rural residents. Nearly four in ten $(43.3 \%)$ had no formal education (Table 1). 
Table I Socio-Demographic Characteristics of Referred Patients Among Health Centers in the Eastern Zone of Tigray, Ethiopia, $2019(n=421)$

\begin{tabular}{|c|c|c|}
\hline $\begin{array}{l}\text { Socio-Demographic } \\
\text { Variables }\end{array}$ & Frequency(n) & $\begin{array}{l}\text { Percentage } \\
\text { (\%) }\end{array}$ \\
\hline \multicolumn{3}{|l|}{ Sex } \\
\hline Female & 236 & 56.7 \\
\hline Male & 180 & 43.3 \\
\hline \multicolumn{3}{|l|}{ Age } \\
\hline $18-24$ & 107 & 24.3 \\
\hline $25-34$ & 123 & 30.1 \\
\hline $35-44$ & 98 & 24 \\
\hline$\geq 45$ & 88 & 21.6 \\
\hline \multicolumn{3}{|l|}{ Marital Status } \\
\hline Married & 278 & 66.8 \\
\hline Never Married & 99 & 23.8 \\
\hline Divorced or Widowed & 39 & 9.4 \\
\hline \multicolumn{3}{|l|}{ Occupation } \\
\hline Governmental & 44 & 10.6 \\
\hline Student & 66 & 15.9 \\
\hline Farmer & 92 & 21.8 \\
\hline Housewife & 110 & 26.4 \\
\hline Merchant & 59 & 14.2 \\
\hline Unemployed & 30 & 7.2 \\
\hline Others & 21 & 5 \\
\hline \multicolumn{3}{|l|}{ Religion } \\
\hline Orthodox & 320 & 76.9 \\
\hline Muslim & 34 & 8.2 \\
\hline Catholic & 38 & 9.1 \\
\hline Protestant & 24 & 5.8 \\
\hline \multicolumn{3}{|l|}{ Residence } \\
\hline Rural & 254 & 61.4 \\
\hline Urban & 160 & 38.6 \\
\hline \multicolumn{3}{|l|}{ Educational Status } \\
\hline No Education & 180 & 43.3 \\
\hline Primary & 62 & 14.9 \\
\hline Secondary & 139 & 33.4 \\
\hline$\geq 12$ & 35 & 8.4 \\
\hline
\end{tabular}

Notes: Other in occupational status includes NGO worker and pension.

\section{Client Level of Satisfaction Toward Different Components of Referral Service} In this study, from the total clients who participated in the study clients were less satisfied with the easiness of the referral 159 (38.2\%) followed by time spent to get referral $162(38.9 \%)$. On the contrary, half of the clients were satisfied with the notification of the referral, and being professional and responsiveness of the health care provider (Table 2).

\section{Overall Client's Satisfaction Toward Referral Service of Health Centers}

From the total referred clients who participated in this study, near half $47 \%$ CI $95 \%$ (38-50) were satisfied with the referral service (rated $>75 \%$ ) and $53 \%$ were unsatisfied with the referral service (rated $<75 \%$ ) (Figure 1).

\section{Factors Associated with Satisfaction Toward Referral Service}

In the multivariable analysis, Age, Educational status, and Residence were significantly associated with patient satisfaction toward referral service of the Health Centers. Model for the goodness of fit was checked using the Hosmer-Lemeshow which estimated a p-value of 0.415 (Table 3).

\section{Discussion}

In this study out of the total clients who participated 159 $(38.2 \%)$ of them were less satisfied with the easiness of the referral followed by time spent to get referral 162 (38.9\%). On the contrary, half of the clients were satisfied with the notification of the referral, and being professional and responsiveness of the health care provider. Long waiting time to get a referral would keep delays in providing and receiving services to a minimum.

This study revealed that $47 \% 95 \% \mathrm{CI}(38-50)$ of referred clients from Health Centers were satisfied. This indicated that significant numbers of referred patients were dissatisfied. This indicated that the Health center may have a poor quality of referral service. As a result, patients may be less likely to come to Health Center to seek care, which could also indicate that Health Center has weak teamwork, weak organizational leadership, and no commitment to improve it. This result is lower as compared to the study done in Nigeria $(52.3 \%),{ }^{5}$ and Iraq $(67 \%){ }^{4}$ The possible reason for the difference could be the difference in the availability of essential resources, both human (staff number and skill to manage the referral), and physical (infrastructure, transport), and as well as communication and coordination of the referring and receiving health facilities. The overall satisfaction rate toward referral was consistent with studies conducted in other services such as inpatient service satisfaction $46.2 \%,{ }^{12}$ which is higher than studies done in the outpatient service satisfaction $27.8 \%{ }^{13}$ But the result of this study is lower as studies done in the emergency service satisfaction $56 \%,{ }^{14}$ antenatal care service satisfaction $73.3 \% .^{15}$ 
Table 2 Client Level of Satisfaction Toward Different Components of Referral Service Among Referred Client by Health Centers in the Eastern Zone of Tigray, Ethiopia, $2019(n=421)$

\begin{tabular}{|c|c|c|}
\hline Item & $\begin{array}{l}\text { Satisfied } \\
\mathbf{N}(\%)\end{array}$ & $\begin{array}{l}\text { Dissatisfied } \\
\text { N (\%) }\end{array}$ \\
\hline \multicolumn{3}{|l|}{ Admission Process } \\
\hline I. I was notified of my referral & $208(50.0 \%)$ & $208(50.0 \%)$ \\
\hline 2. The referral process was generally easy, hassle free, and timely & $159(38.2 \%)$ & $257(61.8 \%)$ \\
\hline \multicolumn{3}{|l|}{ Treatment } \\
\hline I. I was satisfied with the care given to me at the health center & $205(49.2 \%)$ & $211(50.8)$ \\
\hline 2. The health care provider is knowledgeable and treatment is appropriate for my referral & $200(48.0 \%)$ & $216(52.0 \%)$ \\
\hline \multicolumn{3}{|l|}{ Communication } \\
\hline I. I was satisfied with the written/verbal communication from the health care provider & $190(45.6 \%)$ & $226(54.4 \%)$ \\
\hline 2. The case manager for my referral was responsive and helpful. & $180(43.3 \%)$ & $236(46.7 \%)$ \\
\hline \multicolumn{3}{|l|}{ Time } \\
\hline I am satisfied with the time spent to get referral & 162(38.9\%) & $254(61.0)$ \\
\hline \multicolumn{3}{|l|}{ Customer Service } \\
\hline I. The staff was professional and responsive & $208(50.0 \%)$ & $208(50.0 \%)$ \\
\hline 2. I was able to get the information I need & $204(49.0 \%)$ & $212(51.0 \%)$ \\
\hline 3. The staff was helpful, courteous, and friendly & $202(48.6 \%)$ & $2 \mid 4(5 \mid .4 \%)$ \\
\hline \multicolumn{3}{|l|}{ Discharge process } \\
\hline I. I received discharge paper to my referral & $205(49.3 \%)$ & $211(50.7 \%)$ \\
\hline 2. I was given an adequate advance notice of my referral from the health center & $207(49.8 \%)$ & $209(50.2 \%)$ \\
\hline \multicolumn{3}{|l|}{ Overall } \\
\hline I. I would recommend this program to a friend or family member & $200(48.0 \%)$ & $216(52 \%)$ \\
\hline 2. I would come back to this health center & $208(50.0 \%)$ & $208(50.0 \%)$ \\
\hline
\end{tabular}

The odd of satisfaction toward referral among the age group of 18-24 were three times higher than the old age one. This could be due to the difficulty in searching the transport by the older one since the majority of the referred patients traveled using private transport, may not be satisfied easily due to the increment of a stressful situation like having a chronic disease and being widowed in older age, and also older patients might need support for their arrival
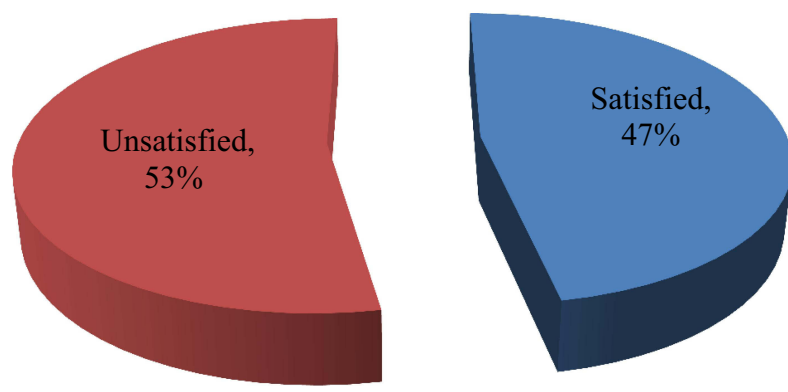

Figure I Overall client satisfaction rate toward referral of Health Centers among Eastern Zone of Tigray, Ethiopia, $2019(n=421)$. to the receiving health facility than younger age, older people may expect more. The finding of this study is in line with the study conducted in Iraq. ${ }^{4}$ This result is different from another study in which older patients were more likely to be satisfied than the young ones.

Similarly, in this study clients who reside in the urban area were two times more likely to be satisfied with the referral of Health Centers than clients who reside in the rural. This might be due to rural residents may face challenges such as transport to arrive at the referral destination health facility, rural residents travel too long to reach the receiving health facility, rural residents may expend more money, and spent more time to get the service. In addition, majority of the rural resident's educational status is lower than the urban residents, therefore their expectation and awareness toward their right, need, and quality of the referral may be lower than the urban residents. But a study conducted in Iraq displayed that there is no association between residence and satisfaction toward referral. ${ }^{4}$

In this study, occupational status was significantly associated with referral satisfaction in which clients with no 
Table 3 The Multivariable Analysis of Selected Variables in Relation to Client Satisfaction Toward Referral Among Health Centers of Eastern Zone of Tigray, Ethiopia, $2019(n=421)$

\begin{tabular}{|c|c|c|c|c|c|}
\hline \multirow[t]{2}{*}{ Variable } & \multicolumn{2}{|c|}{ Satisfaction } & \multirow[t]{2}{*}{ Crude OR with $95 \% \mathrm{Cl}$} & \multirow[t]{2}{*}{ Adjusted OR with $95 \% \mathrm{Cl}$} & \multirow[t]{2}{*}{$P$ value } \\
\hline & Satisfied(I) & Dissatisfied(0) & & & \\
\hline \multicolumn{6}{|l|}{ Sex } \\
\hline Female & 100 & 136 & 1 & I & 1 \\
\hline Male & 80 & 100 & $2.3(0.2-8.1)$ & I.4(0.7-3.0) & 0.32 \\
\hline \multicolumn{6}{|l|}{ Age } \\
\hline $18-24$ & 59 & 48 & $4.2(2.3-12.0) *$ & $3.1(2.3-6.4) *$ & $0.031 *$ \\
\hline $25-34$ & 23 & 100 & $2.1(0.1-9.1)$ & I.3(0.I-2.0) & 0.31 \\
\hline $35-44$ & 40 & 58 & $3.5(0.7-10.7)$ & I.2(0.2-2.4) & 0.60 \\
\hline$\geq 45$ & 30 & 58 & 1 & 1 & 1 \\
\hline \multicolumn{6}{|l|}{ Marital Status } \\
\hline Married & 178 & 100 & I & I & 1 \\
\hline Never Married & 30 & 69 & I.I(I.3-9.4)* & $1.3(0.7-2.7)$ & 0.56 \\
\hline Divorced or Widowed & 10 & 29 & $3.0(0.6-7.5)$ & I.2(0.4-3.7) & 0.82 \\
\hline \multicolumn{6}{|l|}{ Occupation } \\
\hline Governmental & 26 & 18 & 1 & 1 & 1 \\
\hline Student & 26 & 40 & I.2(0.9-8.I) & $0.9(0.6-5.1)$ & 0.91 \\
\hline Farmer & 70 & 22 & $2.0(0.3-5.2)$ & I.I (0.2-3.8) & 0.13 \\
\hline Housewife & 55 & 55 & $1.9(0.3-10.1)$ & I.4(0.3-6.9) & 0.42 \\
\hline Merchant & 20 & 39 & $2.1(0.6-2.3)$ & I.2(0.5-7.7) & 0.94 \\
\hline Unemployed & 6 & 29 & $1.9(0.2-7.5)$ & $1.3(0.1-9.0)$ & 0.31 \\
\hline \multicolumn{6}{|l|}{ Religion } \\
\hline Orthodox & 200 & 120 & I & I & 1 \\
\hline Muslim & 10 & 24 & I.I(I.3-I.9)* & I.2(0.2-8.2) & 0.82 \\
\hline Catholic & 20 & 18 & $2.0(0.7-5.2)$ & I.7(0.4-7.I) & 0.91 \\
\hline Protestant & 4 & 20 & $2.5(0.5-14.0)$ & I.I (0.8-3.1) & 0.53 \\
\hline \multicolumn{6}{|l|}{ Residence } \\
\hline Rural & 200 & 54 & I & I & I \\
\hline Urban & 140 & 20 & $1.9(2.2-4.3) *$ & $2.2(1.3-1.5) *$ & $0.01 *$ \\
\hline \multicolumn{6}{|l|}{ Educational Status } \\
\hline No Education & 130 & 50 & $2.5(2.1-10.7) *$ & $2.1(1.7-4.9) *$ & $0.03 *$ \\
\hline Primary & 30 & 32 & I.2(0.2-5.I) & I.2(0.3-4.3) & 0.14 \\
\hline Secondary & 110 & 29 & $2.0(0.5-4.1)$ & $1.6(0.6-5.1)$ & 0.33 \\
\hline$\geq 12$ & 15 & 20 & I & I & I \\
\hline
\end{tabular}

Notes: $* \mathrm{p}<0.05$ shows Significant factors.

Abbreviations: $\mathrm{COR}$, crude odds ratio; $\mathrm{AOR}$, adjusted odds ratio; $\mathrm{Cl}$, confidence interval.

education was two times more likely to be satisfied than clients with higher educational level. This might be due to client with higher educational level expect more based on the national guidelines in which this may not be applied in practice, and clients with higher educational level may have a short time to return back right to their work, and, a client with no educations expectation and awareness toward their right, need, and quality of the referral may be lower than higher educational level.
But in other previous studies, there was no association between referral satisfaction and educational level. ${ }^{4}$

Even though there was no statistical association between sex and referral satisfaction in this study, a study done in Iraq showed that females were more likely to be satisfied than males. The possible explanation for this might be due to sample size difference. In this finding, the other sociodemographic characteristic shows no significant association. 


\section{The Implication of the Study}

The result of this study has implications for health care policy maker, researcher, and clients. This result is very critical for the health care policymaker and health care providers to work toward the quality improvement of the referral service. It will be also significant for a researcher as a baseline data.

\section{Limitation of the Study}

There might be social desirability bias as this study was carried out at a health facility. There was limited similar literature for comparison of the finding.

\section{Conclusion}

The overall satisfaction rate toward referral service provided by Health Centers in the Eastern Zone of Tigray, Ethiopia was low. Age of the referred client, educational status, and residences were statistically significant sociodemographic factors toward the referral satisfaction. In addition, significant clients were dissatisfied with the time spent to get a referral, easiness of the referral process, the helpfulness and responsiveness of the case manager, and communication. So, the Health Centers management and health care provider should work to reduce time spent to get referral, to reduce challenges in the referral process, increase helping and giving response for the referred clients, to improve communication.

\section{Data Sharing Statement}

The datasets used for this study are available from the corresponding author (Fre Gebremeskel) on reasonable request.

\section{Ethical Approval and Consent to Participate}

The Research and Ethical Committee of the School of Public Health, Addis Ababa University approved this study. The notification code number given to the Title was ERC/006/2019. A formal letter was submitted to Tigray Health Bureau and Health Centers. After getting permission from the Tigray Health Bureau, informed consent was obtained from all participants of the study before the interview which clearly describing the privacy of the respondents, the right to anonymity, right to refuse, confidentiality was secured all the time. Besides, those respondents were also briefed about the aim and benefit of the study. Collected data was stored in different areas not to lose it was stored in a secured place to secure confidentiality, and backup of the data was used. Therefore, this study was conducted in accordance with the Declaration of Helsinki.

\section{Consent for Publication}

Consent for publication is not applicable.

\section{Acknowledgments}

We would like to express our heartfelt gratitude to the data collectors for their cooperation throughout the data collection time and also for all study participants for providing us their information.

\section{Funding}

There was no any specific fund for the study.

\section{Disclosure}

The authors declared no potential conflicts of interest with respect to the research, authorship, and/or publication of this article.

\section{References}

1. An Introduction to Quality Assurance in Health Care - Avedis Donabedian. Oxford University Press. Available from: https://global. oup.com/academic/product/an-introduction-to-quality-assurance-inhealth-care-9780195158090?cc=us\&lang=en\&. Accessed June 8, 2021.

2. Institute of Medicine (US) Committee on Quality of Health Care in America. Crossing the Quality Chasm: A New Health System for the 21st Century [Internet]. Washington (DC): National Academies Press (US); 2001. Available from: http:/www.ncbi.nlm.nih.gov/books/ NBK222274/. Accessed June 8, 2021.

3. Duff-Brown AB Poor quality health care leads to 5 million deaths each year in poorer nations [Internet]. Scope. 2018. Available from: https://scopeblog.stanford.edu/2018/09/11/poor-quality-health-careleads-to-5-million-deaths-each-year-in-poorer-nations/. Accessed June $14,2021$.

4. Abutiheen A. Clients' satisfaction with referral system in Karbala. Am $J$ Appl Sci. 2013;20(11):216-222.

5. Referral Services under the National Health Insurance Scheme; a Hospital-Based Descriptive Cross-Sectional Study in Abuja, Nigeria. 2019 Available from: http/paper/Referral-Services-under-the-NationalHealth-Scheme\%3B/c394c0cea63a231f4549a3f1263cd2d5c2b35af2. Accessed June 14, 2021.

6. Ethiopia Health Sector Transformation Plan (2015/16-2019/20)Global Financing Facility. Available from: https://www.globalfinancingfaci lity.org/ethiopia-health-sector-transformation-plan-201516-201920. Accessed June 8, 2021.

7. Abebe E, Teshome H, A Bekele . Referral of emergency surgical patients in a tertiary hospital, addis ababa, Ethiopia. Ethiop Med J. 2016;52(1)Available from https://emjema.org/index.php/EMJ/article/ view/333.

8. Abdi WO, Salgedo WB, Nebeb GT. Magnitude and determinants of self-referral of patients at a General Hospital, Western Ethiopia. Sci J Clin Med. 2015;4(5):86. doi:10.11648/j.sjcm.20150405.12

9. Kamau KJ, Osuga BO, Njuguna S. Challenges facing implementation of referral system for quality health care services in Kiambu County, Kenya. Health System Policy Res. 2017;04(1). doi:10.21767/22549137.100067 
10. Abdella K National Cancer Control Plan of Ethiopia.: 2015.

11. M Health in Ethiopia: strategies for a new framework: [report]. 2011. Available from: http://bibalex.org/baifa/en/resources/document/ 452566. Accessed June 14, 2021.

12. Asamrew N, Endris AA, Tadesse M. Level of patient satisfaction with inpatient services and its determinants: a study of a specialized hospital in Ethiopia. J Environ Public Health. 2020;13(2020): e2473469.

13. Fufa BD, Negao EB. Satisfaction of outpatient service consumers and associated factors towards the health service given at Jimma Medical Center, South West Ethiopia. PROM. 2019;3(10):347-354. doi:10.2147/PROM.S220404
14. Gebru AA, Mosadeghrad AM, Sari AA, Tafesse TB, Kahsay WG. Client satisfaction on Emergency department services and quality of emergency medical care in Ethiopia: a systematic review. Hum Antibodies. 2019;27(S1):23-31. doi:10.3233/HAB-190367

15. Birhanu S, Demena M, Baye Y, Desalew A, Dawud B, Egata G. Pregnant women's satisfaction with antenatal care services and its associated factors at public health facilities in the Harari region, Eastern Ethiopia. SAGE Open Med. 2020;Jan(8):2050312120973480.

\section{Publish your work in this journal}

Patient Preference and Adherence is an international, peer-reviewed, open access journal that focusing on the growing importance of patient preference and adherence throughout the therapeutic continuum. Patient satisfaction, acceptability, quality of life, compliance, persistence and their role in developing new therapeutic modalities and compounds to optimize clinical outcomes for existing disease states are major areas of interest for the journal. This journal has been accepted for indexing on PubMed Central. The manuscript management system is completely online and includes a very quick and fair peer-review system, which is all easy to use. Visit http:// www.dovepress.com/testimonials.php to read real quotes from published authors. 